\title{
NOTAS SOBRE A ANÁLISE ECONÔMICA DO DIREITO E SUA \\ UTILIZAÇÃO NA APLICAÇÃO DE DECISÕES JUDICIAIS
}

\section{NOTES ON THE ECONOMIC ANALYSIS OF LAW AND ITS USE IN THE APPLICATION OF JUDICIAL DECISIONS}

\author{
Demetrius Nichele Macei ${ }^{1}$ \\ Fábio Veiga ${ }^{2}$ \\ Juliano Siqueira de Oliveira ${ }^{3}$
}

\section{Resumo}

O fenômeno da interdisciplinaridade entre o Direito e a Economia, calcado na maximização da conduta humana que lhe renderá o maior bem-estar, não pode ser relegado a segundo plano, mas recepcionado e estudado e utilizado como forma de criação de uma nova perspectiva do direito. A experiência demonstra que está esgotada a possibilidade de que os fenômenos sociais sejam explicados tão somente à luz do produto da dogmática jurídica formal, tornando-se latente a necessidade de que tais fenômenos sejam analisados e compreendidos pelo Direito capaz de recepcionar os mecanismos oriundos do pensamento econômico. Assim, o presente artigo, a partir da metodologia dedutiva e revisão bibliográfica, analisou a possibilidade de aplicação do pensamento econômico e alguns de seus instrumentos para a obtenção de soluções jurídicas e judiciais mais eficientes e compatibilizadas ao cumprimento dos objetivos constitucionais da República Federativa do Brasil, concluindo por sua possibilidade e receptividade no cenário jurídico nacional tendo em vista a constatação de adoção de premissas do pensamento e da ciência econômica em decisão judicial exarada pelo Supremo Tribunal Federal por ocasião do Julgamento da Ação Direta de Inconstitucionalidade n. ${ }^{\text {o } 2591 / D F . ~}$

\footnotetext{
${ }^{1}$ Pós-doutorado na Faculdade de Direito do Largo São Francisco (USP). Doutor em Direito Tributário pela Pontifícia Universidade Católica de São Paulo (2012). Mestre em Direito Econômico e Social (2004) e Especialista em Direito Empresarial (2000), ambos pela Pontifícia Universidade Católica do Paraná, Bacharel em Direito pela Universidade Federal do Paraná (1994). Professor de Direito Tributário na graduação, especialização, mestrado e doutorado na Faculdade de Direito Curitiba (UNICURITIBA)

${ }_{2}^{2}$ Advogado, mestrando do Programa de Especialização Stricto Sensu Direito Empresarial e Cidadania do Centro Universitário Curitiba.

${ }^{3}$ Advogado, mestrando do Programa de Especialização Stricto Sensu Direito Empresarial e Cidadania do Centro Universitário Curitiba.
} 
Palavras-chave: Análise Econômica do Direito. Decisões Judiciais.

\begin{abstract}
Resumen/Résumé
The phenomenon of interdisciplinarity between law and economics, based on the maximization of human conduct that will yield the greatest welfare, can not be relegated to the background, but welcomed, studied and used as a way of creating a new perspective of law. Experience shows that the possibility that social phenomena can be explained only in the light of the product of formal legal dogma is exhausted, which means that the phenomena need to be analyzed and understood by the law capable of receiving mechanisms from thought economic. Thus, this article intends to analyze the possibility of applying economic thinking and some of its instruments to obtain legal and judicial solutions that are more efficient and compatible with the fulfillment of the constitutional objectives of the Federative Republic of Brazil.
\end{abstract}

Keywords: Economic Analysis of Law. Judicial Decisions.

\title{
1. INTRODUÇÃO
}

Trata o presente artigo de fazer uma revisão bibliográfica sintética de obras de referência para compreensão da Análise Econômica do Direito (AED), e avaliar a decisão do Supremo Tribunal Federal na ADI 2.591/DF, à luz de conceitos econômicos, a título de ilustração. Com isso, espera-se contribuir para divulgação da AED como uma matriz teórica relevante para o Direito brasileiro.

Inevitável é o reconhecimento de que as relações mantidas entre pessoas que compõem determinado grupo social se desenvolvem, aprimoram e modernizam em velocidade muito superior àquela em que se efetivam o desenvolvimento, aprimoramento e modernização das regras jurídicas que balizam esse convívio social. Por isso, não raras vezes esse é o caminho que leva a uma abrupta separação entre o regramento de uma sociedade e a realidade das relações dos indivíduos que a compõem (que, aliás, deveria ser subjacente àquele) e que resta materializada pela existência de um direito "nobre e oficial, o único admitido nas discussões acadêmicas e nos debates doutrinários, e um direito menos qualificado ou de segundo grau, destinado a completar e corrigir o primeiro.” (COMPARATO, 1965, p. 37-38). 
Trata-se, em verdade, do reconhecimento de que o direito (ou o primeiro "direito" acima apontado por Comparato, ínsito à dogmática formal tradicional e estanque a quaisquer influências externas) em algum momento deixou de se bastar em si mesmo, passando a cabalmente sofrer influência de aspectos e elementos inerentes à economia. Para Cordobera (2008, p. 22), tratou-se de um verdadeiro acerto que, sob essa perspectiva, "el nuevo derecho econômico el hecho de sostener que nos es posible entender las instituciones jurídicas a luz de critérios puramente jurídicos sino que es necessário contar com el contenido econômico"4.

Diante disso, pode-se dizer que o primeiro registro de sua origem pode ser remontado à influência da primeira guerra mundial sobre as economias, a qual demonstrou que em períodos de confrontos como o ora destacado, todos os setores da sociedade passam a ser influenciados diretamente, senão regidos diretamente, pela guerra, que será ganha, em grande medida, a partir da atuação de determinados setores da iniciativa privada. Ou seja, a partir do momento em que a sorte do Estado na guerra estaria necessariamente atrelada à atividade industrial, desenvolvida pela iniciativa privada, observou-se que caberia ao referido ente público regular de maneira mais atenta as atividades econômicas privadas a fim destas se mostrarem capazes de atender aos interesses e necessidades do Estado em guerra. O mesmo Fábio Konder Comparato (1965, p.39) assentou:

\footnotetext{
O fenômeno não passou sem registro na doutrina. Mas enquanto alguns nesse viam apenas a formação de um direito bélico, de natureza excepcional e transitória, outros ousaram afirmar o nascimento de uma nova forma de expressão jurídica, um novo ramo do direito que, transcendendo o fenômeno especificamente militar que lhe dera origem, estava fadado a durar e se impor na vida social: tratar-se ia de um direito de economia ou direito econômico, corolário indispensável da constituição do Estado pós-liberal.
}

Relevante apontar que, com o advento da crise da bolsa norte americana de 1929, fez necessária a intervenção do Estado para a movimentação da economia a fim de incentivar a produção industrial e a criação de vagas de empregos, buscando-se, desta forma, o reequilíbrio da economia, Referido evento, outrossim, logo fora sucedido pelo advento da segunda guerra mundial, a qual trouxe penúria, grave crise econômica e a necessidade de reconstrução das nações severamente atingidas pelas batalhas ocorridas, o que levou o Estado, conclamado a intervir no cumprimento destas tarefas, a

\footnotetext{
${ }^{4}$ Tradução livre: o novo direito econômico o fato de sustentar que é possível entender instituições jurídicas à luz de critérios puramente legais mas é necessário contar com o conteúdo econômico
} 
dispor de novos instrumentos voltados à obtenção de recursos, o que fez por meio de medidas tais quais o incentivo à formação e captação de recursos de poupança e a emissão de títulos da dívida pública em concorrência aos particulares, de modo que "o Direito deixa-se assim penetrar de conteúdo econômico, ao mesmo tempo em que a Economia torna-se sempre mais administrativa ou regulamentada, isto é, jurídica". (COMPARATO, 1965, p. 40).

O que se observa, inegavelmente, é que o direito decorrente de uma produção dogmática tradicional, unidisciplinar e compartimentada, que, segundo Souza (2009) "conduz a um isolamento entre as próprias disciplinas, cada qual fazendo de seu método e de seus conceitos a única vertente possível para se chegar a verdade" mostrou-se incapaz de atender aos fatos sociais relevantes que marcaram grandes eventos do século $\mathrm{XX}$, os quais conduziram a um caminho pelo qual o regramento social estatal realizado a partir do Direito não mais prescindiria da adoção de conceitos econômicos na formação das normas e na investigação dos fenômenos sociais.

\section{LINHA CRONOLÓGICA DA ANÁLISE ECONÔMICA DO DIREITO}

Nesta senda, Mackaay e Rousseau (2015, p.8) pontuam que "a ideia de recorrer a conceitos econômicos para melhor compreender o direito não é nova. Remonta a Maquiavel, Hobbes e Locke, bem assim aos filósofos escoceses do Século das Luzes". Ao seu turno, Ribeiro e Galeski Junior (2009, p. 54), citando Mackaay, pontuam que o movimento da Análise Econômica do Direito estaria assentado na Escola Clássica, liderada por Adam Smith, que "crê na liberdade de concorrência como solução para a melhor alocação dos recursos, tendo em vista que os preços seriam livremente formados pelo mercado, alcançando-se o equilíbrio". Para Comparato (1965, p. 45) a noção primeira de economia política estava atrelada a uma concepção estática da vida econômica inerente ao Estado Liberal, calcado em um equilíbrio obtido sem intervenções externas entre a produção e a circulação de riquezas, enquanto que "a concepção atual da vida econômica, como da vida social em geral é essencialmente dinâmica. A ciência social de nossos dias, dominada pela ideia de evolução e de processo, desconhece os equilíbrios; ela conhece tão somente (...) tendências finalistas.". 
Ainda que diversos integrantes do movimento critiquem referido autor, seu posicionamento possibilita a fundação de uma doutrina pela qual a intervenção estatal somente se justificaria em caso de falhas de mercado e consequente causação de maiores danos ao mercado pela, então, não intervenção do que pela atuação direta do ente estatal no caso concreto.

A contribuição de Jeremy Bentham também é significativa, na medida em que expoente do utilitarismo, pelo qual "deveria o homem agir para maximizar a felicidade (prazer) e evitar a dor, o que justificaria suas condutas" (RIBEIRO e GALESKI JUNIOR, 2009, p 55). O utilitarismo é uma das bases filosóficas da análise de custo e benefício empreendida na seara econômica e, por conseguinte, relevante para a Teoria da Análise Econômica do Direito.

A respeito do tema e de que maneira a teoria econômica joga luz sobre o elemento da utilidade, Araújo (2007, p. 14) faz distinção bastante didática da análise iminentemente jurídica daquela realizada sob a ótica econômica do contrato, ao pontuar que:

\footnotetext{
Não é irrelevante de modo algum para a análise econômica que o caráter vinculativo do contrato resulte de uma intenção jurídica de respeito pela autonomia moral dos promitentes, ou de objetivos de prevenção do dano que a desvinculação poderia causar à confiança dos credores; simplesmente, as abordagens econômicas preferem incidir, seja na utilidade criada pelas trocas consumadas (admitindo assim que haja hipóteses de desvinculação eficiente), seja no caráter incentivador que ex ante revestirá a adstrição jurídica forte às obrigações contratuais, fazendo neste segundo caso ressaltar a utilidade imediatamente criada pela própria vinculação (o valor da confiança), que suplementará a utilidade a gerar futuramente pela consumação das trocas que sejam objeto do acordo contratual.
}

Mackaay e Rousseau (2015), retomando a linha cronológica do desenvolvimento da Análise Econômica do Direito assentam que o movimento atualmente existente liga-se a duas correntes antecedentes, sendo elas (i) a do imperialismo econômico, a qual faz uso de instrumentos da análise econômica no campo político, família, ou seja, em campos não tradicionalmente abordados por critérios de análise econômica; e (ii) a do realismo jurídico, para quem as disciplinas da economia e sociologia integravam diretamente o direito.

O início do movimento remonta à Universidade de Chicago que, a partir de 1958, passou a publicar a revista Journal os Law and Economics, veículo utilizado pelos economistas daquela escola para a divulgação de seus estudos na área do direito, sendo manifestamente relevante o artigo de Ronald Coase denominado The Problem of 
Social Cost, acerca dos custos de transação, "o que se converteu em um dos pilares da análise econômica do direito" (MACKAAY e ROUSSEAU, 2015, p. 10).

Segundo Ribeiro e Galeski Junior (2009), ao abordar a referida teoria, "as empresas só tem utilidade porque os agentes consideram que realizar o máximo de operações dentro de uma mesma organização econômica evita a ocorrência de acréscimos desnecessários”. E, assertando acerca do Teorema de Coase, Klein (2016, p. 67, 68):

\begin{abstract}
a formulação mais conhecida, entretanto, pode ser assim enunciada: numa situação de custos de transação zero, a alocação final de um bem, obtida por meio de barganha entre as partes, será sempre eficiente, não importa a configuração legal acerca da propriedade desse bem”.

(...)

O fundamento do Teorema pode ser visto em um exemplo tirado do próprio Coase. Imagine uma fazenda utilizada para a pecuária, em que o rebanho invade a fazenda vizinha e destrói a plantação existente. Não importa qual a solução dada pelo direito, se as partes puderem negociar sem custos de transação a solução mais eficiente, sobre como definir a responsabilidade pelos custos causados pelo gado invasor, será o resultado dessa negociação.
\end{abstract}

Além do acima apontado trabalho de Ronald Coase, as obras de Guido Calabresi denominadas The Cost of Accidents e Some thoughs about on risk distribution andthe law torts vem a possibilitar de maneira categórica a realização de uma abordagem econômica de questões iminentemente jurídicas, como indenizações e responsabilidade civil (torts), evidenciando, mais do que isso, que uma adequada abordagem jurídica de tais questões não pode deixar de ser permeada pelos elementos de economia.

Caminhando neste trilho, tem-se que nos anos de 1970 a aceitação do paradigma do movimento da Análise Econômica do direito está assentada na criação do Journal of Legal Studies, cujo primeiro Editor é professor de direito da Universidade de Chicago, Richard A. Posner. A criação do referido periódico possibilita que inúmeros artigos relacionados ao tema do direito e economia sejam publicados e as ideias do movimento difundidas.

Além disso, ao seu turno, em 1972, o mesmo Richard A. Posner, editor do Journal of Legal Studies publica a obra Economic Analysis of Law, a qual representa um marco introdutório ao law and economics, redigido de maneira a tornar-se acessível aos alunos de direito e assim, evidentemente, contribuir para a difusão no território estadunidense dos conceitos da análise econômica do direito. Rapidamente as 
universidades americanas passam a incorporá-la em seus cursos de direito, inclusive em áreas do conhecimento tipicamente dominadas pelas construções dogmáticas do Direito, conforme ensinam MACKAAY e ROUSSEAU (2015, p. 11):

\begin{abstract}
O movimento da análise econômica do direito se impôs, em poucos anos, nas melhores faculdades de direito norte-americanas, como uma corrente de pensamento de primeira importância e até mesmo como principal fonte de renovação da teoria do direito. A maior parte das faculdades de direito oferece cursos usando a análise econômica do direito. Até cursos clássicos, como, por exemplo, sobre bens (property), obrigações (contracts) e responsabilidade (torts), foram modificados, e os professores que os ministram acreditam que não é possível limitar-se ao direito positivo, mas ser necessário dar aos alunos instrumentos - econômicos - para determinar se o direito está adequado para preencher sua função.
\end{abstract}

Necessário destacar que Richard Posner, além de professor do curso de Direito da Universidade de Chicago, exercia o cargo de juiz e, com isso, sua carga de convencimento acerca da necessidade de que o direito seja revisitado pela law and economics não ficou adstrita a estudos acadêmicos. Vale dizer, Posner, citado por Ribeiro e Galeski Junior (2009, p. 60), assentou que "é plenamente possível o exercício da Análise Econômica do Direito na aplicação jurisdicional, afirmando, inclusive, que o direito consuetudinário (...) tende a maior eficiência do que o direito legislado".

Ou seja, Richard A. Posner passou a incorporar a análise econômica à aplicação do direito ao caso concreto que ele, na condição de magistrado, costumeiramente realizava, o que, evidentemente, contribuiu de maneira definitiva para a aceitação das premissas do law and economics nos Estados Unidos da América a partir do momento em que a prestação jurisdicional por ele entregue lastreava-se no referido movimento. Este, portanto, deixava os limites da academia e passava a integrar a realidade do direito aplicado ao caso concreto sob a batuta inicial de Posner.

Acerca da questão, Cordobera (2008, p. 22) ${ }^{5}$, citando Calabresi e Posner, assentou:

Mientras el análisis económico del Derecho es uma corriente más reciente según ya hemos expuesto y se desarrollan em escuelas de derecho americanas como la de Yale de Chicago a través de Guido Calabresi (1984) y Richard Posner (1998). Mantiene puntos em contacto pero su diferencia básica

\footnotetext{
5 Tradução livre: Enquanto a análise econômica do direito é uma tendência mais recente, como temos discutido e desenvolvido nas faculdades de direito americanas, como Yale, em Chicago, através de Guido Calabresi (1984) e Richard Posner (1998). Tem pontos em contato, mas sua principal diferença básica está em tomar como eixo a metodologia de solução de conflitos de interesses, baseada em critérios econômicos como valor, lucratividade, satisfação de necessidades etc., e a influência que têm nas soluções de interpretação jurídica.
} 
essencial radica em tomar como eje la metodología respecto de la solución de conflitos de interesses, sobre la base de critérios económicos como los de valor, rentabilidade, satisfacción de necessidades, etcétera y la influencia que étos presentan em las soluciones de interpretación jurídica.

Neste momento, contudo, passou-se a ecoar estudos acerca das imperfeições e críticas à teoria da Análise Econômica do Direito. Na década de 1980 juristas como Duncan Kennedy, integrante do movimento denominado Critical Legal Studies, criticavam a law and economics. Nada obstante ambos terem origem no Realismo Jurídico, entravam em rota de colisão pelo fato de que aquela escola escorava-se em orientação política de esquerda enquanto esta última calcava-se na orientação liberal ou neoliberal, surgindo, a partir deste ponto, o atrito entre $\mathrm{s}$ movimentos e as críticas desferidas à análise econômica do direito (RIBEIRO e GALESKI JUNIOR 2009).

Na mesma esteira, da Europa, mais especificamente dos integrantes da Escola Austríaca, precursora do movimento denominado marginalista ou neoclássico, advinham críticas pelo fato de que, para esta escola, o ponto central de análise seria a figura do agente e os conceitos de escassez e utilidade - enquanto que os teóricos clássicos calcavam-se na figura das classes de bens - o que faria com que os valores se tornassem subjetivos, variando de acordo com a utilidade de cada bem de indivíduo para indivíduo e, assim, impossibilitando que fosse realizada uma avaliação objetiva de tais interesses e necessidades dos agentes.

No entendimento de Rousseau e Mackaay (2015), “central, no debate, é saber se a atribuição de direitos pode ser deduzida de considerações de eficácia ou se é necessário, para precisar a noção de eficácia, fixar previamente, ao menos, certos direitos fundamentais", sendo que, para referidos autores, a posição ideal é a de reconhecer ser possível a atribuição de direitos a partir de critérios objetivos de eficácia e, assim, aproximam-se os mesmos do utilitarismo.

Por fim, não se pode dizer se houve vencedores ou perdedores no debate travado, então, pela law and economics perante os marginalistas da Escola Austríaca ou mesmo perante os críticos da Critical Legal Studies, sendo tão somente certo que o paradigma aceito no início da década de 1970, submetido às mais variadas discussões acerca de seus fundamentos, ensejou a criação de outras escolas de pensamentos da análise econômica do direito em alternativa à escola de Chicago, tais como a Escola Austríaca, a corrente dos institucionalistas e as correntes ligadas ao Behavioral Law and Economics. 


\section{OS ELEMENTOS DA ANÁLISE ECONÔMICA DO DIREITO}

Pelo que visto até o momento, o estudo do direito não pode prescindir dos elementos da economia, sendo imperiosa a necessidade de criação de um método de estudo do direito a partir dos conceitos econômicos, sendo categórico neste sentido, o posicionamento de Ulen (2017, p. 37), ao defender sua visão de que "o Direito e Economia como a aplicação do método científico de estudo do direito - a aquisição de novos conhecimentos por elaboração de hipóteses, bem como a coleta e análise de dados destinados a confirmar ou refutar tais hipóteses".

A Análise Econômica do Direito, nesta senda, representara um campo do conhecimento que fará uso de elementos da ciência econômica para interpretar e criar o direito, sempre tomando por base suas consequências no mundo real ${ }^{6}$. Sua atuação partirá, portanto, da tentativa de se prever o comportamento humano que será esposado como respostas a certos incentivos para que, assim, se possa criar a melhor regra ou a melhor decisão judicial aplicável ao caso concreto. Logo, a análise está centrada no agente e nas decisões que caberá a ela tomar, sendo certo que, neste sentido, Posner (2010) assenta que a análise econômica possui como pressupostos os fatos de que “indivíduos possuem preferências sobre resultados, de que essas preferências obedecem a condições básicas de consistência e de que indivíduos satisfazem estas preferências com base em limitações orçamentárias exógenas.”. Ou seja, a análise econômica do direito não prescinde do comportamento humano, o qual, segundo o autor, tenderá a preferir os melhores resultados sempre calcados na premissa de que os recursos disponíveis são limitados por circunstâncias externas.

O elemento escolha, portanto, é fundamental e, assim, toda e qualquer situação que envolva escolhas pode ser submetida à análise pelo aspecto econômico, razão pela qual, segundo Gico Jr (2016, p. 19):

(...) quando se fala em análise econômica não estamos nos referindo a um objeto de estudo específico (e.g mercado, dinheiro, lucro), mas ao método de investigação aplicado ao problema, o método econômico, cujo objeto pode ser qualquer questão que envolva escolhas humanas (e.g. litigar ou fazer acordo, celebrar ou não um contrato, poluir ou não poluir).

\footnotetext{
6 Neste aspecto, "em toda análise consequencialista, as regras são julgadas pelos seus efeitos"
} (ROUSSEAU e MACKAAY, 2015, p. 68) 
Assim, a abordagem econômica serve para compreender toda e qualquer decisão individual ou coletiva que verse sobre recursos escassos, seja ela tomada no âmbito do mercado ou não. Toda atividade humana relevante, nessa concepção, é passível de análise econômica.

Deste modo, ao se tratar da análise econômica do direito, o que se tem é a adoção de ferramentas econômicas (tais como os conceitos de escassez de recursos) na interpretação, análise e até mesmo criação do ordenamento jurídico, a partir da busca da maior previsibilidade do comportamento humano e de que maneira o indivíduo responderá a determinado incentivo. Para Ribeiro e Galeski Junior (2009, p. 77) "a ciência econômica gravita em torno dos seguintes princípios: a escolha racional, ou a maximização; o equilíbrio e a eficiência". Para Rousseau e Mackaay (2015), a análise econômica teria três pilares, sendo eles a escassez, a escolha racional e a incerteza, aos quais, outrossim, deveria ser adicionado indivíduo ou a individualidade metodológica.

No que tange à escassez, necessário observar que algo se torna escasso a partir do momento em que o referido bem não se encontra mais à disposição em quantidade suficiente a atender a todos que teriam interesse em obtê-la, sendo que a primeira consequência é a de que caberá aos interessados escolher qual o uso darão à determinada coisa, vez que indisponível na quantidade desejada. Daí também advirá (i) a necessidade de que a coisa não seja desperdiçada, assim como que, por meio do empreendedorismo, novas formas de obtenção da coisa sejam pensadas e desenvolvidas pelo indivíduo; (ii) a conclusão de que a escassez se mostrara com fonte de estabelecimento de direitos; assim como (iii) a conclusão de que, diante de um cenário de escassez de determinado recurso, caberá ao indivíduo fazer escolhas.

Neste ponto, então, a escolha assume papel de grande importância no estudo da análise econômica do direito, sobretudo porque, a fim de trazer o estudo para a previsibilidade, é necessário ponderar que, ao menos em tese, "os agentes econômicos ponderam os custos e os benefícios de cada alternativa, adotando a conduta que, dadas as condições e circunstâncias, lhe traz mais bem-estar" (GICO JR., 2016, p. 22). Portanto, a partir das informações que estão à sua disposição, espera-se que o indivíduo, na busca da decisão que lhe assegure o maior bem-estar, mas em um cenário de escassez de recursos, externe o que pode ser chamado de conduta racional maximizadora.

De acordo com Ribeiro e Galeski Junior (2009) o princípio da escolha racional está ligado à revolução marginalista e à escola austríaca, na medida em que inseriram o conceito de marginalidade na análise econômica e, para tanto, lecionam de 
maneira clara que "marginal é o adjetivo que representa os efeitos de uma pequena variação. Assim, é possível analisar se uma escolha é racional ou não se o benefício marginal exceder o custo marginal".

No entanto, a conduta racional veio a ser alvo de críticas por parte de Herbert Simon, que apontou uma falha decorrente do fato de que as pessoas não possuem as informações necessárias para poderem avaliar todas as possibilidades e consequências inerentes à decisão que será tomada e, ainda que as informações estivessem à disposição, o ser humano sequer teria condições de processá-las adequadamente a fim de exercer a decisão racional maximizadora. Por isso, "se a informação não for levada em conta, de forma seletiva, na decisão, é preciso resignar-se com uma aproximação que substitua a exatidão na tomada de decisão" (ROUSSEAU e MACKAAY, 2015, p. 33), o que é denominado de racionalidade limitada ou bounded rationality.

No que toca à incerteza ${ }^{7}$, destaca-se que o referido elemento é o que impulsiona o indivíduo diante de novos desafios, de modo que somente diante da incerteza o homem estará disposto a buscar meios de inovar e enfrentar a escassez sobretudo voltado a empreender novas formas e ideias voltadas a obter recursos e vencer as dificuldades que lhe são impostas.

Por fim, indispensável ainda abordar o elemento da eficiência. Isso porque, na medida em que, conforme visto, o indivíduo racional tenderá a exercer a escolha que melhor atenda a seus interesses, é certo que a ineficiência destas decisões implicara em uma alocação indevida de recursos, os quais, conforme visto, são escassos e, portanto, não devem ser alvo de desperdícios. Por este motivo, a eficiência é alvo da análise econômica do direito.

O início da abordagem da eficiência econômica deve remontar ao estudo de Vilfredo Pareto, para quem "a eficiência econômica acontece quando se verifica que ao se melhorar a situação de um determinado indivíduo, ou família, ou classe social, necessariamente corresponder-se-á uma piora na situação de um outro indivíduo (...)." (BITTENCOURT, 2016, p. 30). Deste modo, a partir do momento em que os recursos estão distribuídos de forma a que qualquer alteração no estado de uma das partes demandará piora na situação do outro, estar-se-á diante de uma situação ótima de Pareto ou Pareto-eficiente. Adotando o conceito no âmbito contratual, Posner (2010) assenta:

\footnotetext{
${ }^{7}$ Conforme visto alhures, o terceiro pilar da análise econômica do direito para Rousseau e Mackaay
} 
O autor constrói um modelo no qual as partes maximizariam suas utilidades se pudessem celebrar um contrato ótimo. Sem um ordenamento jurídico que garanta o cumprimento das obrigações assumidas, as partes não podem formular tal contrato; então, a questão teórico-especulativa se torna saber qual regra jurídica hipoteticamente proporcionaria às partes atingirem aquele ponto ótimo na celebração do contrato.

Contudo, por levar em consideração somente o bem-estar do indivíduo e o conceito que este possui acerca de seu bem-estar, dispensando quaisquer digressões acerca do aspecto coletivo, o conceito de eficiência de Kaldor-Hicks passou a ganhar força e, segundo seu critério, a escolha é eficiente quanto "a disputa pela alocação de recursos resulta em que o proveito para os vencedores lhes permita compensar os perdedores, a despeito de que realmente assim o façam” (RIBEIRO e GALESKI JUNIOR, 2009, p. 88). Denota-se que o cerne do critério reside na alocação de recursos que beneficie a todos - ao contrário do que se observava na teoria de Pareto, calcada nos critérios individualistas de maximização de bem-estar e conceituação de bem-estar - na busca da maximização das riquezas.

Trazendo o conceito, uma vez mais, para o aspecto contratual, TIMM (2015, p. 181), esclarece que o "aumento na riqueza total da sociedade é o que os economistas chamam de excedente econômico de uma transação. Quando um contrato tiver excedente econômico maior que zero, ele trará um resultado eficiente". Ou seja, a eficiência está calcada no critério que possibilita a maior alocação de recursos na sociedade, vale dizer, na acima mencionada maximização de riquezas, por meio de decisões eficientes externadas por seus indivíduos.

\section{A ANÁLISE ECONÔMICA DO DIREITO NAS DECISÕES JUDICIAIS}

Na medida em que possui viés consequencialista, ao tentar prever os comportamentos que serão externados pelos indivíduos a partir dos incentivos criados, a análise econômica do direito passa a ter dois vieses diferenciados, os quais caracterizam a análise econômica do direito dita positiva e a análise econômica do direito dita normativa (GICO JR, 2016). Abordando a diferenciação entre elas, Posner (2010), leciona que: 
prescritivos. A AED positiva, então, esforça-se em mostrar como as normas jurídicas evoluíram de modo a agregar eficiência à sociedade, diminuindo o custo das transações e estimulando as relações econômicas. Já a AED normativa emitirá opiniões sobre a adequação ou não de determinadas regras jurídicas a fins últimos.

Diante disso, é certo que a análise econômica do direito poderá atuar de maneira descritiva, explicando a norma e sua racionalidade, assim como as consequências previstas a partir dos comportamentos previstos ou, então, sob o viés normativo, atuando de maneira a possibilitar a escolha da decisão mais eficiente. Neste ponto, é certo que os critérios da análise econômica não ficariam adstritos à contribuição para a formação das normas jurídicas, havendo sua irradiação para o campo das decisões judiciais. Sopesar as consequências econômicas das decisões judiciais passa a representar "uma necessidade premente de legitimação de eficácia da ciência jurídica". (SOUZA, 2009, p. 285), sobretudo porque a dogmática formal não mais se mostra capaz de fazer frente às demandas e reivindicações de direitos.

De fato, embora haja apontamento de que são poucas as decisões a invocar expressamente a AED (MEYER-PFLUG e PEGHINI, 2018, 19), outros autores notam número crescente de decisões judiciais inspiradas ou orientadas por critérios econômicos. PARGENDLER e SALAMA (2015, p. 43) afirmam ser crescente a adoção dos critérios econômicos na formulação de decisões judiciais, na medida em que os tribunais vem atraindo para si a tarefa de implantação de políticas públicas, de modo que "condicionada a níveis mínimos de alfabetização econômica, a intervenção judicial na formulação de políticas é a variável relevante para explicar o surgimento da análise econômica na prática do Direito".

Necessário sempre ter em mente, contudo, que a análise econômica, nestes casos, não estará presente somente em decisões relacionadas a assuntos mais diretamente influenciados a conceitos econômicos, mas também quando se busca a previsão das consequências decorrentes da norma e, assim, da decisão judicial que será aplicada. A partir do momento em que, como visto, o Poder Judiciário tem se aproximado da elaboração de políticas, necessário que esteja ele dotado de mecanismos ou instrumentos capazes de possibilitar a análise dos comportamentos previsíveis em resposta a estas políticas e, assim, tenham elementos para as consequências das decisões.

De outro lado, PARGENDLER e SALAMA (2015, p. 49, 55) pontuam a existência de três fatores que tornam propícia a propagação do pensamento econômico 
nas decisões judiciais, sendo eles (i) o aspecto ideológico marcado pela atuação progressista do Estado brasileiro, estabelecida pela Constituição Federal de 1988 no momento em que é colocado sobre os ombros do Estado a obrigação de promover ações concretas, objetivas e positivas para a criação e execução de políticas públicas e objetivos como os estabelecidos no artigo $3^{\circ}$ da Constituição federal; (ii) a ascensão do Poder Judiciário decorrente de sua atuação mais intensa na criação e efetivação de tais direitos, políticas públicas e objetivos do Estado estabelecidos na Constituição Federal; e por fim, (iii) o fator jurídico, calcado no fato de que a atuação mais assente do Judiciário, conforme visto, se opera dentro de um sistema legal que, assim, precisa se mostrar apto a recepcionar essas alterações ocorridas na estrutura das normas, de modo que se enseja aumento da necessidade de utilização do raciocínio econômico, o que se dá, "de duas maneiras: ao incorporar diretamente as consequências econômicas ao conteúdo das normas legais e ao tornar a aplicação de um determinado regime legal quanto à conveniência de suas consequências".

A fim de ilustrar a adoção do pensamento econômico junto aos tribunais, a questão discutida no bojo da Ação Direta de Inconstitucionalidade n. ${ }^{\circ}$ 2.591/DF demonstra de maneira bastante reluzente a adoção de critérios econômicos para dirimir uma controvérsia eminentemente jurídica. A referida Ação Direta de Inconstitucionalidade fora proposta pela Confederação Nacional do Sistema Financeiro - Consif com o objetivo de afastar da incidência do Código de Defesa do Consumidor, mais precisamente do conceito de "serviço" albergado no Artigo $3^{\circ}, \S 2^{\circ}$, aqueles prestados pelas instituições financeiras referentes ao custo das operações ativas e a remuneração das operações passivas desenvolvidas pelas instituições financeiras, em vista, outrossim, da disposição original do artigo 192, § $3^{\circ}$ da Constituição Federal, que exigia a regulamentação do sistema financeiro por meio de lei complementar e, portanto, estabelecia:

\footnotetext{
Art. 192. O sistema financeiro nacional, estruturado de forma a promover o desenvolvimento equilibrado do País e a servir aos interesses da coletividade, será regulado em lei complementar, que disporá, inclusive, sobre:

(...)

$\S 3^{\circ}$ As taxas de juros reais, nelas incluídas comissões e quaisquer outras remunerações direta ou indiretamente referidas à concessão de crédito, não poderão ser superiores a doze por cento ao ano; a cobrança acima deste limite será conceituada como crime de usura, punido, em todas as suas modalidades, nos termos que a lei determinar.
} 
Denota-se claramente que a controvérsia instaurada aduzia diretamente aos consumidores e ao mercado financeiro, sendo necessária a análise das consequências que poderiam advir do reconhecimento de que o Código de Defesa do Consumidor teria o condão de regular a taxa de juros de mercado, consoante claramente abordado pelo Voto do Ministro Carlos Velloso:

\subsection{POSSÍVEIS CONSEQÜÊNCIAS DA APLICAÇÃO DO CDC ÀS OPERAÇÕES TÍPICAS DO SFN.}

Antes de mais nada, sabe-se que os agentes econômicos atuam de forma a maximizar lucros e a reduzir prejuízos. Essa lógica se aplica ao mercado bancário. Como vimos, a TAXA DE JUROS cobrada pelo BANCO do MUTUÁRIO e a paga pelo BANCO ao DEPOSITÁRIO são fixadas a partir de um conjunto de fatores tendo como elemento principal o valor da TAXA BÁSICA DE JUROS. Se o teto de cobrança dos juros não estiver atrelado à POLÍTICA MONETÁRIA do governo, existiria claramente um "descasamento" entre o que o BANCO tem a receber (ativo) e o que se obrigou a pagar (passivo).

O dinheiro necessário a equilibrar essa equação viria de outras fontes, tais como tarifas bancárias, que teriam que ser majoradas, ou mesmo da necessidade de subsídio público para tal equilíbrio. Na hipótese, o ônus recairia sobre o usuário, o contribuinte ou ambos. Do contrário, a própria atividade bancária estaria inviabilizada.

(...)

A POLÍTICA ECONÔMICA, na vida democrática, é da competência das autoridades governamentais. É o Governo o responsável pela formulação dessa política. A legitimação para tal vem da vitória nas eleições. Entender-se de outra forma, é comprometer a atividade financeira no Brasil.

Vale dizer, denota-se abordagem explícita das consequências possíveis decorrentes da relegação à lei ordinária (Código de Defesa do Consumidor) da taxa de juros praticada no mercado financeiro, evidenciando-se claramente o consequencialismo que marca a análise econômica do direito. Do mesmo modo, relevante a análise de trecho do voto do Ministro Eros Grau:

5. É certo, no entanto, que o $\S 2^{\circ}$ do art. $3^{\circ}$ do Código de Defesa do Consumidor há de ser interpretado em coerência com a Constituição. Para tanto se impõe sejam excluídos da abrangência por seus efeitos determinação do custo das operações ativas e da remuneração das operações passivas praticadas por instituições financeiras na exploração da intermediação de dinheiro na economia. A respeito dessa matéria deve dispor o Poder Executivo, a quem incumbe fiscalizar as operações de natureza financeira, o que envolve a fixação da taxa base de juros praticável no mercado financeiro.

A fixação dessa taxa não pode ser operada senão desde a perspectiva macroeconômica. Basta a menção, por exemplo, ao poder de multiplicação de moeda circulante em moeda escritural, que os bancos exercem de modo a receber a título de juros, pelo mesmo dinheiro materialmente considerado, em certos casos mais de três vezes o valor da taxa praticada. O volume de moeda adicional "criado" pelo banco corresponde a moeda escritural, isto é, a moeda bancária --- moeda que, na dicção de Eugênio Gudin7, "só se concretiza nos 
livros dos bancos, através de algarismos que passam de um a outro livro ou de uma a outra coluna. Esses algarismos são animados pela vontade das partes mas não saem dos estabelecimentos de crédito, onde nascem, circulam e desaparecem".

Ainda que a Corte, no que pertine ao presente trabalho, tenha assentado entendimento no sentido de que todas as instituições financeiras estejam sob o regime jurídico do Código de Defesa do Consumidor, concluiu-se que, ao se outorgar interpretação constitucional aos termos do artigo $3^{\circ}, \S 2^{\circ}$ do Código de Defesa do Consumidor, "o custo das operações ativas e a remuneração das operações passivas praticadas por instituições financeiras na exploração da intermediação de dinheiro na economia estejam excluídas da sua abrangência", conforme item 3 da ementa do acórdão exarado. Se assim não fosse, a ingerência de critérios puramente jurídicos sobre a economia teria o condão de afetar a sustentabilidade do mercado financeiro, colocando em risco as condições mínimas necessárias para o próprio atingimento dos objetivos constitucionais entabulados no artigo $3^{\circ}$ da Carta da república de 1988.

Fica claro, assim, que a solução cunhada pelo Supremo Tribunal Federal não levou em consideração tão somente os elementos oriundos da dogmática jurídica, realizando-se o cotejo das consequências que adviriam sobre o mercado financeiro em caso de se admitir que a lei ordinária promovesse, de maneira estanque, a regulamentação legal da taxa de juros.

Entende-se que a situação analisada é semelhante àquela já antes identificada por TOMAZETE $(2007,177)$ e assim exposta por ele:

Embora, sem usar diretamente a expressão análise econômica do direito, o
Supremo Tribunal Federal já aplicou tal concepção, como por exemplo, no
caso do pedido de Intervenção Federal no Estado de São Paulo (IF 2.127-SP)
por não cumprimento de decisão judicial referente ao pagamento de
precatório. Não havia dúvida, quanto à ausência do cumprimento das
decisões judiciais, mas decretar a intervenção não seria uma medida eficiente,
não iria garantir a maximização da riqueza.

Ou seja, não se pode afirmar que o Supremo Tribunal Federal tenha realizado uma análise econômica da decisão nos termos da AED, porém sim considerou os efeitos

\footnotetext{
${ }^{8} \mathrm{O}$ autor ainda refere voto do Gilmar Ferreira Mendes, cujo trecho merece reprodução: "Desse modo, não podem ser desconsideradas as limitações econômicas que condicionam a atuação do Estado quanto ao cumprimento das ordens judiciais que fundamentam o presente pedido de intervenção. Nesse sentido, constam do memorial apresentado pelo Estado de São Paulo, os seguintes dados (...) Como tenho afirmado, esse exame de dados concretos, ao invés de apenas argumentos jurídicos, não é novidade no direito comparado. No âmbito dos reflexos econômicos da atividade jurisdicional, a experiência internacional tem, assim, demonstrado que a proteção dos direitos fundamentais e a busca da redução das desigualdades sociais necessariamente não se realizam sem a reflexão acurada acerca de seu impacto."
} 
econômicos (consequências) de sua decisão e os ponderou como razão influente no julgamento, tal como já havia feito em momento anterior.

\section{CONCLUSÃO}

A apropriação de conteúdos econômicos como chave para a abertura da porta da multidisciplinariedade vem se mostrando, ao longo do tempo, elemento capaz de contribuir de maneira relevante para a criação de condições que permitam uma alocação mais adequada de recursos na economia e, com isso, políticas públicas mais eficientes. O Direito não pode se mostrar alheio às consequências que a aplicação de seus institutos impõem à sociedade, de modo que lançar mão da análise econômica do direito, tanto no viés descrito (AED positiva) quanto no viés normativo, apoiando, portanto, os diplomas legais e as decisões judiciais se mostram como elementos absolutamente importantes para a busca de um cenário jurídico e um ordenamento legal, na medida do possível, situado a partir da previsibilidade das condutas que serão externadas pelos administrados, assim como, especialmente, em que as possíveis consequências sejam previamente identificadas.

De outro lado, a aplicação do direito ao caso concreto não deve deixar de ter como norte elementos econômicos como o da escassez de recursos, sobretudo porque o desenvolvimento da atividade empresarial está manifestamente balizado por esta realidade.

É certo que a construção de decisões judiciais calcadas nos preceitos da análise econômica do direito terá o condão de ensejar maior segurança jurídica, sobretudo por estarem amparadas em critérios objetivos de validade e no rigor metodológico econômico, possibilitando, deste modo, que a Economia e seus instrumentos passem a ficar à disposição do Direito e não vice-versa. 


\section{REFERÊNCIAS}

ARAÚJO, Fernando. Teoria Econômica do Contrato. Coimbra. Almedina, 2007.

BRASIL. Constituição (1988). Publicação Original. Disponível em http://www2.camara.leg.br/legin/fed/consti/1988/constituicao-1988-5-outubro-1988322142-publicacaooriginal-1-pl.html. Acesso em 06/02/2019.

BRASIL. Lei n. ${ }^{\circ}$ 8.078 de 11 de setembro de 1990. Dispõe sobre a proteção do consumidor e dá outras providências. Disponível em http://www.planalto.gov.br/ccivil_03/LEIS/L8078.htm. Acesso em 06/02/2019

BRASIL. Supremo Tribunal Federal. Ação Direta de Inconstitucionalidade n. 2.591/DF. Requerente: Confederação Nacional do Sistema Financeiro - Consif. Requeridos Presidente da República e o Congresso Nacional. Relator Ministro Carlos Velloso. 07/06/2016. Disponível em http://redir.stf.jus.br/paginadorpub/paginador.jsp?docTP=AC\&docID=266855. Acesso em 04/06/2019.

BITTENCOURT, Mauricio Vaz Lobo. Princípio da eficiência. In: RIBEIRO, Marcia Carla Pereira; KLEIN, Vinicius (coord.). O que é análise econômica do direito: uma introdução. $2^{a}$ edição. Belo Horizonte. Forum, 2016.

COMPARATO, Fábio Konder. O indispensável direito econômico. In Revista dos Tribunais. Ano 101. Vol. 923, setembro/2012

CORDOBERA, Lidia Maria Rosa Garrido. La negociació contractual y el análisis econômico. In Pensar: Revista do Curso de Direito da Universidade de Fortaleza. Vol. 13, n. 1, jan/jun 2008

GICO JR., Ivo T. Introdução à análise econômica do direito. In: RIBEIRO, Marcia Carla Pereira; KLEIN, Vinicius (coord.). O que é análise econômica do direito: uma introdução. $2^{a}$ edição. Belo Horizonte. Forum, 2016. 
GONÇALVES, Everton das Neves; STELZER, Joana. Eficiência e direito: pecado ou virtude; uma incursão pela análise econômica do direito.. Revista Juridica, [S.1.], v. 1, n. 28, p. 77-122, nov. 2012. ISSN 2316-753X. Disponível em: <http://revista.unicuritiba.edu.br/index.php/RevJur/article/view/412/317>. Acesso em: 20 abr. 2020. doi:http://dx.doi.org/10.21902/revistajur.2316-753X.v1i28.412.

MACKAAY, Ejan; ROUSSEAU, Stéphane. Análise Econômica do direito. Tradução Rachel Sztajn. $2^{a}$ ed. São Paulo. Atlas, 2015.

MEYER-PFLUG, Samantha Ribeiro; PEGHINI, Aline Aparecida Santos Costa. A Teoria do Direito: Uma Análise da Influência do Law And Economics na Construção do Pós-Positivismo. Revista de Direito do Trabalho, v. 191, p. 19 - 38, Jul / 2018.

PARGENDLER, Mariana; SALAMA, Bruno. In POMPEU, Ivan Guimarães; BENTO, Lucas Fulanete Gonçalves; POMPEU, Renata Guimarães (Coord). Estudo sobre negócios e contratos: uma perspectiva internacional a partir da análise econômica do direito. Almedina, 2017.

POSNER, Eric. Análise econômica do direito contratual: sucesso ou fracasso? [tradução e adaptação ao direito brasileiro: Luciano Benetti Timm, Cristiano Carvalho e Alexandre Viola]. São Paulo, Saraiva, 2010.

RIBEIRO, Marcia Carla Pereira; JUNIOR, Irineu Galeski. Teoria Geral dos contratos: contratos empresariais e análise econômica. Rio de Janeiro. Elsevier, 2009.

SOUZA, Artur César. Análise econômica das decisões judiciais. In WAMBIER, Teresa Arruda Alwim (Coord). Revista de Processo. Ano 34, n. 17, out/2009.

TIMM, Luciano Benetti. Direito Contratual Brasileiro: críticas e alternativas ao solidarismo jurídico. $2^{\mathrm{a}}$ ed. São Paulo. Atlas. 2015

TOMAZETE, Marlon. A Viabilidade da Análise Econômica do Direito no Brasil. Revista Tributária e de Finanças Públicas, v. 75, p. 177 - 198, Jul - Ago / 2007. 
ULEN, Thomas S. Direito e Economia para todos. In POMPEU, Ivan Guimarães; BENTO, Lucas Fulanete Gonçalves; POMPEU, Renata Guimarães (Coord). Estudo sobre negócios e contratos: uma perspectiva internacional a partir da análise econômica do direito. Almedina, 2017.

VELOSO, Sílvia Mechelany. Análise econômica da função social dos contratos Art. 421 do Código Civil. In NERY JR, Nelson; NERY, Rosa Maria de Andrade (Coord) Revista de Direito Privado. Ano 14, vol. 54. Abr-jun. 2013. 